\title{
Heat transfer in a confined impinging jet with swirling velocity component
}

\author{
Karel Petera ${ }^{\mathrm{a}}$, Martin Dostál \\ Czech Technical University in Prague, Department of Process Engineering, Technická 4, Praha 6, Czech Republic
}

\begin{abstract}
Heat transfer measurements based on an infrared experimental method (TOIRT) are compared with CFD simulations of a confined impinging jet with tangential velocity component. The tangential velocity component added to a pure impinging jet introduces into the flow field and heat transfer some similarities with real industrial processes like agitated vessels with axial-flow impellers. The tangential velocity component significantly influences the velocity field and heat transfer intensity in the stagnant region when compared to the classic impinging jet characteristics. Several turbulence models were used in numerical simulations of an agitated vessel with axial-flow impeller in a draft tube. Heat transfer coefficients at the vessel bottom were evaluated using the TOIRT method and compared with numerical results. The lateral heat conduction in the impinged wall was analysed with the conclusion that it has relatively small impact on the measured heat transfer coefficients. Quite good agreement of experimental data and simulation results was achieved concerning the size and position of the heat transfer maximum at the vessel bottom.
\end{abstract}

\section{Introduction}

High heat transfer intensities at relatively small surfaces can be achieved with impinging jets putting them in the focus of industrial interest. Various experimental, numerical and analytical data concerning the hydrodynamics and heat or mass transfer in impinging jets can be found in the literature, mainly in a configuration where the fluid (liquid) jet impinges a smooth plane surface [1-4]. In practice, many impinging jets are generated by devices with rotary parts therefore some tangential (swirling) velocity component is always present at the jet nozzle which has a significant impact on the velocity profile. Figure 2 illustrates the influence of the tangential velocity component on the axial velocity profile. A tangential velocity component linearly increasing from zero at the center to the maximum value at the jet radius was superposed on a developed axial velocity profile in a pipe at Reynolds number $\operatorname{Re}=23000$. It was then used as the inlet boundary condition of the jet nozzle. Due to centrifugal forces induced by the swirling velocity component, the parabolic-shaped velocity profile in the axial direction was transformed to a triangle-shaped velocity profile at the nozzle outlet (length $L=2 d$ ), see Figure 2 . It is clearly visible there that the axial velocity component approaches zero values near the center.

A similar velocity profile can be observed at the outlet of the draft tube in an agitated vessel with an axial-flow impeller, see Figure 3. Similarities of velocity profiles between an unconfined impinging jet with a swirling velocity component and a real industrial equipment like the agitated vessel can be clearly identified here. The question is how much they influence the temperature field and if some similarities can be identified in the heat transfer as well.

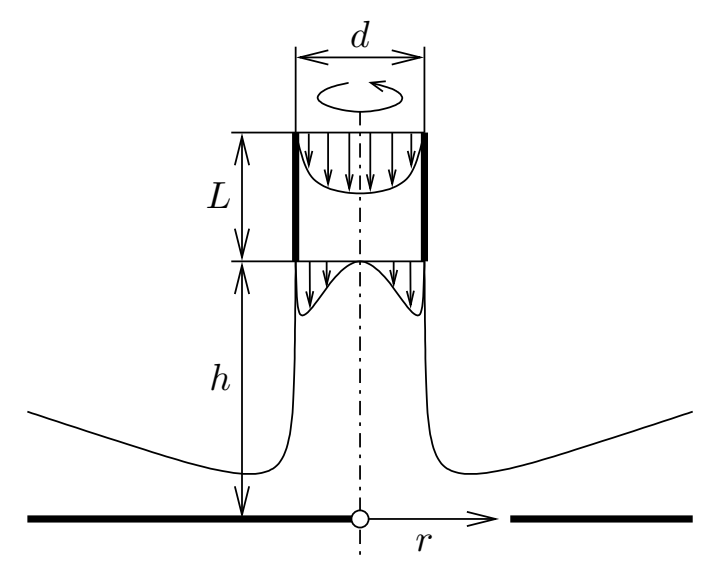

Figure 1: A scheme of a jet with nozzle length $L$, diameter $d$, and distance $h$ from the impinged plate.

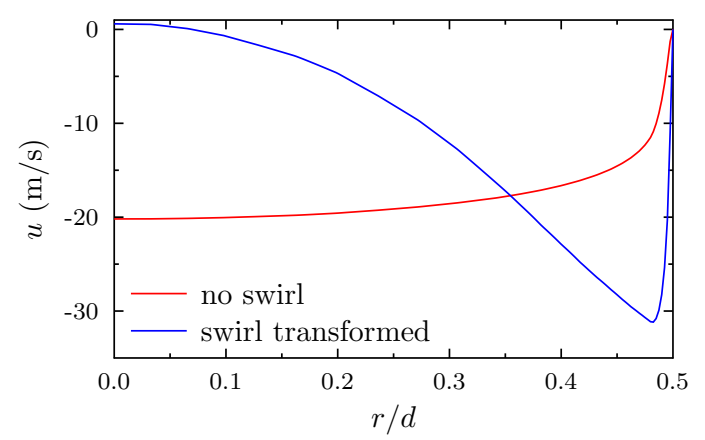

Figure 2: The axial velocity profile transformation due to centrifugal forces induced by the tangential (swirling) velocity component. $h / d=2, \operatorname{Re}=23000$, Swirl number $S=1.02$ (Eq. 3).

a Corresponding author: karel.petera@fs.cvut.cz 

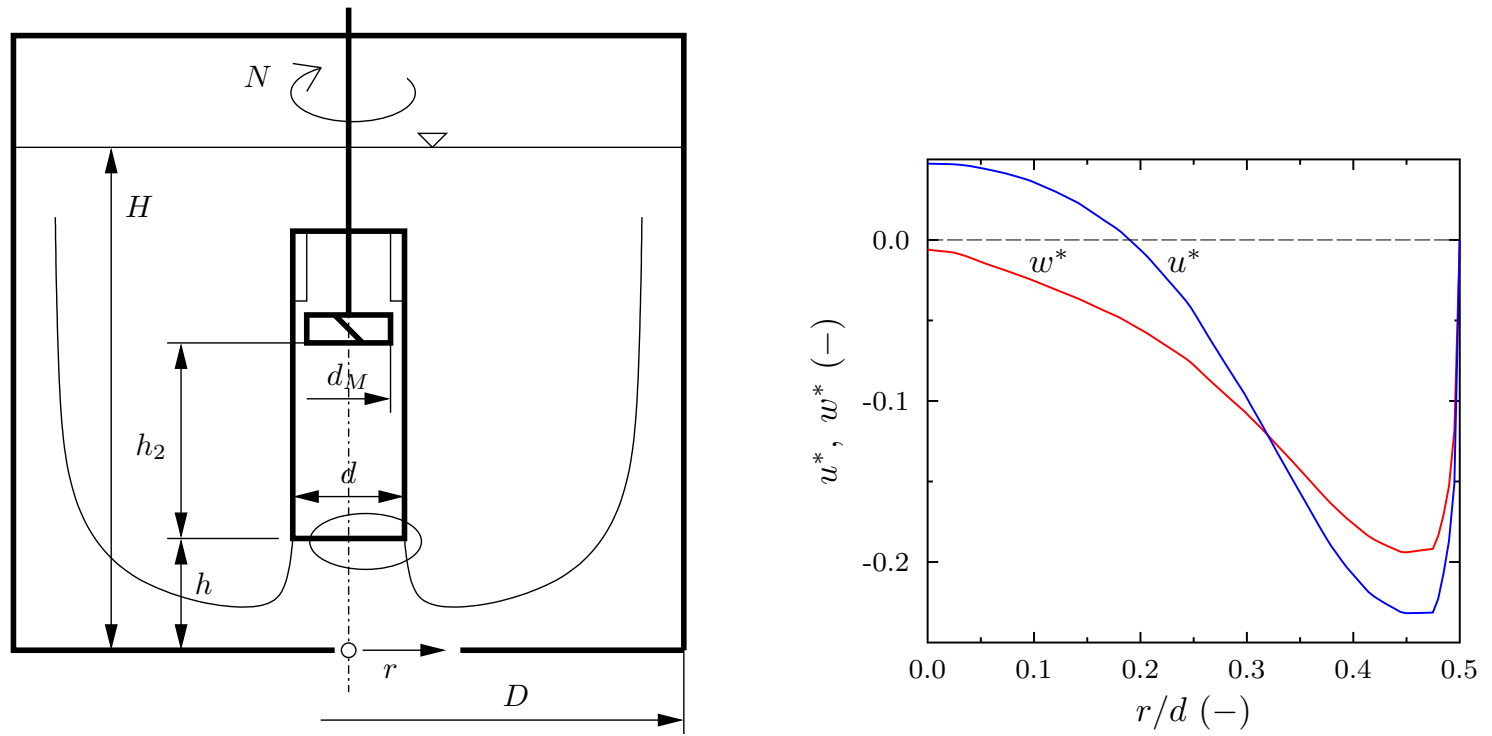

Figure 3: Geometrical configuration of a confined impinging jet generated by an axial-flow impeller in a draft tube, with an example of typical axial and tangential velocity profiles at the outlet of the draft tube [5].

As demonstrated on Figure 2, the axial velocity profile of a swirling impinging jet differs significantly from a nonswirling case which should have a large impact on heat transfer, especially in the stagnation region where the axial velocities are quite small or even negative. Figure 4 illustrates the difference between the swirling and non-swirling jet for frequently published case with Reynolds number $\operatorname{Re}=23000$ and distance to nozzle diameter ratio $h / d=2$. A large drop in Nusselt number values is visible at the center of the stagnation region which is a consequence of small values of the axial velocity components there. It is in accord with some of the literature data [6], even though as pointed out by [7], the flow and heat transfer characteristics show drastically different results depending on the type of swirl generators. In our case, we have used an axialflow impeller with six blades, $45^{\circ}$ pitch angle, and diameter $d_{\mathrm{M}}=61 \mathrm{~mm}$. It was placed in a draft tube with inner diameter $70 \mathrm{~mm}$. The distance of the draft tube from the vessel bottom was $70 \mathrm{~mm}$, giving the ratio of height and jet diameter as $h / d=1$. The vessel diameter was $D=392 \mathrm{~mm}$, and liquid height $H=430 \mathrm{~mm}$. The position of the impeller in the draft tube was $h_{2}=215 \mathrm{~mm}$ above the tube outlet. The total tube length was $300 \mathrm{~mm}$, therefore the top part of the tube was $60 \mathrm{~mm}$ below the liquid surface. In the upper part of the draft tube, small $60 \mathrm{~mm}$ long baffles were installed to prevent a whirl formation.

The axial-flow impeller produced a jet with tangential (swirling) velocity component at the outlet of the draft tube, which, in addition, belongs to the category of confined impinging jets because it is placed in a cylindrical vessel. In this paper, we compared CFD simulation results with experimental data measured by the TOIRT (infra-red temperature-oscillation) method [8].

\section{Numerical simulation of agitated vessel}

We have used ANSYS CFD with Fluent solver version 16.0 to perform our numerical simulations and get comparison with experimental data. ANSYS Meshing component

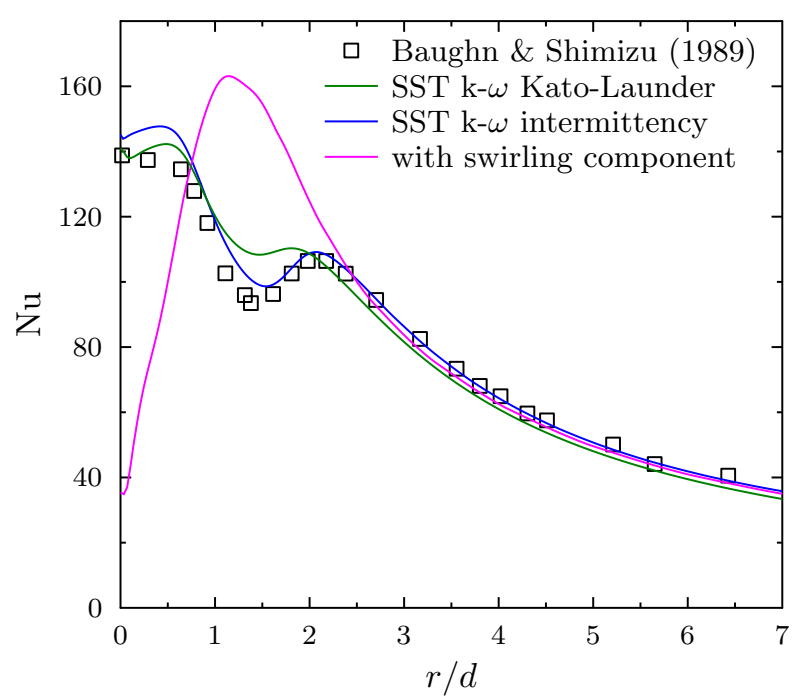

Figure 4: Comparison of the Nusselt number values for air impinging jets with and without tangential/swirling velocity component. $\operatorname{Re}=23000, h / d=2$, Swirl number at the outlet of the draft tube $S=1.02$ (1.27).

was used to create a mesh on the geometry depicted on Figure 3 . We have made a mesh independence study with several mesh sizes and we finally used a mesh with 2.2 million of cells. Inflation layers were used near the vessel and draft tube walls, as well as the impeller itself. As we were interested in the heat transfer at the vessel bottom, the inflation layers were created there so that $Y^{+}$quantity was close to the recommended value 1 and the near-wall region was fully resolved with no approximations by wall functions. In our case, the maximum value of $Y^{+}$was 1.8 which we found sufficient.

We used RANS (Reynolds averaged Navier-Stokes) turbulence models [9] which are less computationally expensive than LES-based or even DNS approaches. With RANS models, the Reynolds stress tensor in the time-averaged 
Navier-Stokes equation must be somehow defined, i.e. the system of equations must be closed. A simpler definition is based on the Boussinesq eddy-viscosity approximation [10] which assumes that the Reynolds (turbulent) stress tensor is proportional to mean strain-rate tensor $S_{i j}$ and the proportional factor is eddy (turbulent) viscosity $\mu_{\mathrm{t}}$.

$$
-\varrho \overline{u_{i}^{\prime} u_{j}^{\prime}}=2 \mu_{\mathrm{t}} S_{i j}-\frac{2}{3} \varrho k \delta_{i j}
$$

In this work, we mainly used Realizable $k-\varepsilon$ and SST $k-\omega$ models which uses another set of (transport) equations for quantities like turbulence kinetic energy $k$ and energy dissipation $\varepsilon$ or specific dissipation rate $\omega$ to express turbulent viscosity $\mu_{\mathrm{t}}$ in the Equation (1), for example

$$
\mu_{\mathrm{t}}=\alpha^{*} \frac{\varrho k}{\omega}
$$

According to our previous work [11], we put more preferences to SST $k-\omega$ model with Kato-Launder limiter [12] as it resolves the excessive production of turbulence kinetic energy caused by a very high level of shear stress rate in the stagnation regions [13]. Without this limiter, the Nusselt number values were usually overpredicted near the stagnation point in our numerical simulations of an unconfined impinging jet with no swirling component [11]. Kato-Launder limiter is enabled by default in the ANSYS Fluent implementation of the SST $k-\omega$ Intermittency Transition model which gave us best agreement with experimental data for free impinging jets [11]. With SST $k-\omega$ model, Kato-Launder limiter must be turned on manually in the Fluent solver.

We used the MRF (Moving/Multiple Reference Frame) [13] approach to get the velocity field in the agitated vessel with the draft tube. First, we started with a steadystate simulation, and then we switched to the transient case when the vessel bottom was heat by a constant heat flux. After an initial transient period ( 2 seconds) we gathered the temperature field (wall) statistics over a larger time period $(10-20$ seconds), and we evaluated the heat transfer coefficients (Nusselt numbers) at the vessel bottom. Figure 5 presents a comparison of the Nusselt number values at the bottom of the agitated vessel for several turbulence models. A large drop in the heat transfer intensity near the stagnation point is in accordance with our simulations of the unconfined impinging jet (see Figure 4). Of course, there are huge differences from the unconfined jet near the vertical wall where the stream of fluid decelerates due to the presence of the wall and changes its direction up along the vertical wall of the vessel. A recirculation zone is visible in the flow field here, see Figure 6, which has a direct consequence in the jumps of the heat transfer intensities near the vertical wall.

The results of the numerical simulations presented in this section are then used in comparison with experimental data in the subsequent text as well as in the analysis of the TOIRT method. The impeller speed $400 \mathrm{rpm}$ corresponded to the swirl intensity represented by Swirl number $S=1.1$ in the case of the following definition [14]

$$
S=\frac{2}{d} \frac{G_{\varphi}}{G_{x}}
$$

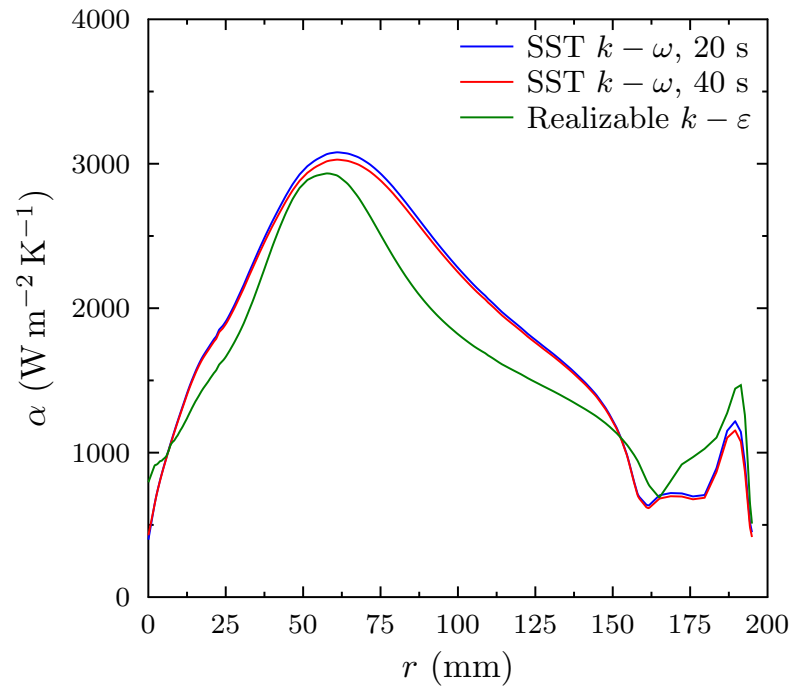

Figure 5: Comparison of the Nusselt number values at the bottom of the agitated vessel for impeller speed $400 \mathrm{rpm}$ (mixing Reynolds number 25000 ), constant heat flux boundary condition and several turbulence models. A comparison of two time intervals (20s and 40s) used in transient statistics collection for SST $k-\omega$ model with Kato-Launder limiter [12] is presented here.

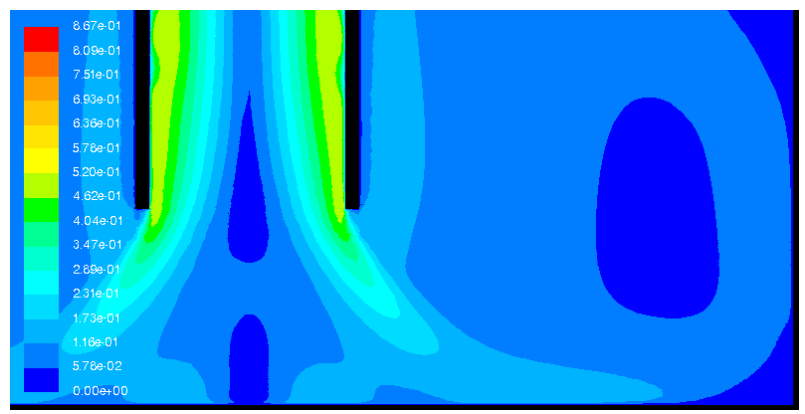

Figure 6: Contours of velocity magnitude below the draft tube and near the vessel bottom, $400 \mathrm{rpm}$, Swirl number $S=1.1(0.7)$, SST $k-\omega$ turbulence model.

where $G_{\varphi}$ and $G_{x}$ represent the flux of angular and axial momentum's, respectively.

$$
G_{\varphi}=\int_{A} \varrho r u w \mathrm{~d} A, \quad G_{x}=\int \varrho u^{2} \mathrm{~d} A
$$

In the literature, a different and simpler definition of the Swirl number is also used [7]

$$
S=\frac{w_{\mathrm{b}}}{u_{\mathrm{b}}}
$$

where $w_{\mathrm{b}}$ and $u_{\mathrm{b}}$ represent the bulk tangential (azimuthal) and axial velocities, respectively.

$$
u_{\mathrm{b}}=\frac{1}{A} \int_{A} u \mathrm{~d} A, \quad w_{\mathrm{b}}=\frac{1}{A} \int_{A} w \mathrm{~d} A
$$

This simpler definition (6) of the Swirl number gives value 0.7 for our case of impeller speed $400 \mathrm{rpm}$.

\section{TOIRT experimental method}

The temperature oscillation method accompanied by the contactless temperature measurements using infra-red ther- 


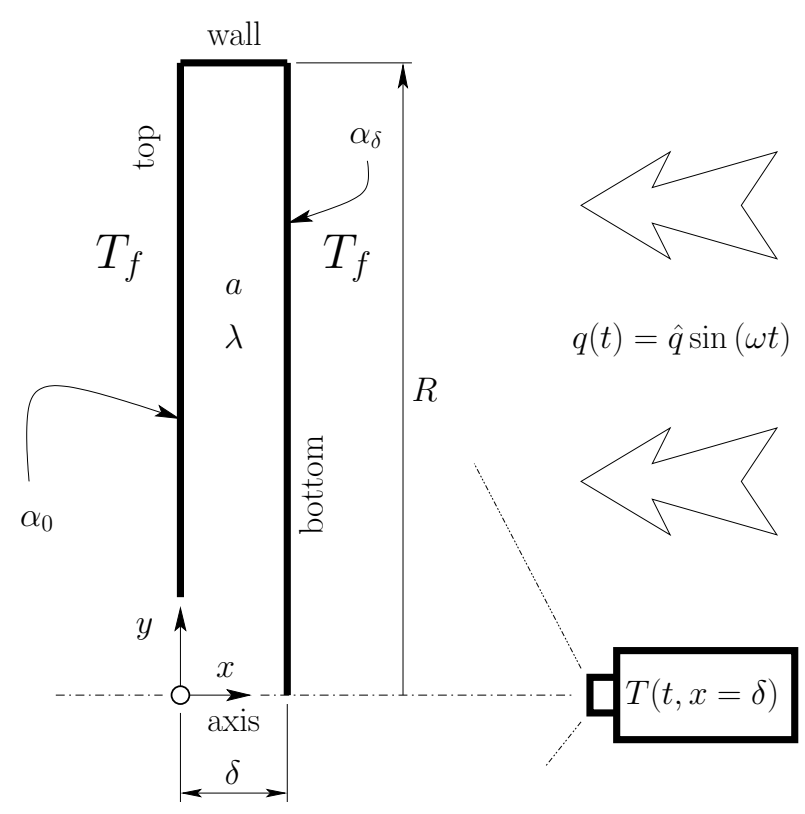

Figure 7: The principle of the TOIRT method by Wandelt and Roetzel [8]. The left side of the wall (denoted as "top") is impinged by a stream of fluid, the right side ("bottom") is heated by an oscillating heat flux. The temperature response $T(t, x=\delta)$ is then measured by an infrared camera.

mography (Temperature Oscillation Infra-Red Thermography, TOIRT) was used to measure and verify the heat transfer coefficient along the impinged heat transfer surface. Freund [15] measured the temperature response of a plate induced by an oscillating heat flux impinging the plate which was an extension of work by [8]. See [16-18] for more details and applications of this method.

The principle of the TOIRT method is depicted on Figure 7. It is based on measuring the time dependency of $\left.T\right|_{x=\delta}$ (or other corresponding characteristic) at the surface plate of width $\delta$ induced by oscillating heat flux $\left.q\right|_{x=\delta}$. The temperature response depends on thermophysical properties of the plate and heat transfer coefficients on both sides of the plate, i.e. $\alpha_{0}$ and $\alpha_{\delta}$. Transient temperature field $T$ in a homogeneous plate with thermal diffusivity $a$ is described by the Fourier equation

$$
\frac{\partial T}{\partial t}=a\left(\frac{\partial^{2} T}{\partial x^{2}}+\frac{\partial^{2} T}{\partial y^{2}}+\frac{\partial^{2} T}{\partial z^{2}}\right) .
$$

Neglecting the lateral heat conduction described by the last two terms on the right-hand side and adding boundary conditions on both sides of the plate, it is possible to find an analytical solution for the case of a periodically oscillating impinging heat flux. The boundary conditions of the third kind can be applied on both sides, with a periodic oscillation of the heat flux on one side. Assuming zero temperatures $T_{f}$ on both sides, they can be described as

$$
\begin{gathered}
\left.\lambda \frac{\partial T}{\partial x}\right|_{x=0}=\left.\alpha_{0} T\right|_{x=0}, \\
\left.\lambda \frac{\partial T}{\partial x}\right|_{x=\delta}=\hat{q} \sin \omega t-\left.\alpha_{\delta} T\right|_{x=\delta},
\end{gathered}
$$

where $\lambda$ is thermal conductivity of the plate, $\omega$ is frequency of the oscillating heat flux with amplitude $\hat{q}$, and $\alpha_{0}, \alpha_{\delta}$ are the already mentioned heat transfer coefficients on both sides of the plate. Using the Laplace transform, a temperature solution on both sides of the plate for amplitude $A$ and phase shift $\varphi$ can be found [8]

$$
T(x, t)=A(x) \sin (\omega t-\varphi(x)) .
$$

Then, the phase shift at the surface with induced temperature oscillations $(x=\delta)$ can be described [8] as

$$
\begin{aligned}
& \left.\tan \varphi\right|_{x=\delta}= \\
& \frac{c_{1}+2 \xi \psi_{0} c_{2}+2 \xi^{2} \psi_{0}^{2} c_{3}}{2 \xi \psi_{0}(1+r) c_{0}+2 \xi^{2} \psi_{0}^{2}(1+2 r) c_{1}+4 \xi^{3} \psi_{0}^{3} r c_{2}+c_{3}}
\end{aligned}
$$

where the following dimensionless variables and parameters are used

$$
\begin{aligned}
r=\alpha_{\delta} / \alpha_{0}, & \psi_{0}=\frac{\alpha_{0}}{\delta \varrho c_{\mathrm{P}} \omega}=\frac{\alpha_{0} a}{\delta \lambda \omega}, \quad \xi=\delta \sqrt{\frac{\omega}{2 a}} \\
c_{0}= & \cosh ^{2} \xi \cos ^{2} \xi+\sinh ^{2} \xi \sin ^{2} \xi \\
c_{1}= & \cosh \xi \sinh \xi+\cos \xi \sin \xi \\
c_{3}= & \cosh ^{2} \xi \sin ^{2} \xi+\sinh ^{2} \xi \cos ^{2} \xi \\
c_{4} & =\cosh \xi \sinh \xi-\cos \xi \sin \xi
\end{aligned}
$$

It is maybe not clear from the complicated solution (11), but the phase shift of the temperature response depends on the size of unknown heat transfer coefficient $\alpha_{0}$, and, on the contrary, it does not depend on the amplitude of the heat flux. Furthermore, it does not depend on the accuracy of the oscillating temperature field measurements. In this case with the neglected lateral heat conduction, it is not necessary to measure the surface temperature precisely, only the exact time dependency between the impinging heat flux and the measured temperature response is required.

\section{Experimental}

As mentioned in the previous section denoted to the numerical simulations of the agitated vessel, the heat transfer coefficients at the surface impinged by a stream of fluid (liquid) with a superposed tangential (swirling) velocity component differ significantly from the case with no tangential component. In this section, the aim is to verify the numerical results for the case of the confined swirling impinging jet generated by the axial-flow impeller in a cylindrical vessel with the draft tube.

The heat transfer coefficient in an impinging jet was measured on a circular plate (bottom of the vessel) with diameter $392 \mathrm{~mm}$ and thickness $1 \mathrm{~mm}$. The plate was made of steel with thermal conductivity $14.6 \mathrm{~W} \mathrm{~m}^{-1} \mathrm{~K}^{-1}$, density $7800 \mathrm{~kg} \mathrm{~m}^{-3}$ and specific heat capacity $501 \mathrm{~J} \mathrm{~kg}^{-1} \mathrm{~K}^{-1}$. Water was used as the fluid and its temperature was within the range $25^{\circ} \mathrm{C}$ to $29^{\circ} \mathrm{C}$ during all measurements. The temperature change of water was up to $2^{\circ} \mathrm{C}$ during one measurement.

The oscillating heat flux impinging the other (bottom) side of the plate was generated by $3 \times 500 \mathrm{~W}$ halogen lamp. The light intensity modulation, that is the size of the impinging heat flux, was maintained using the voltage variation within range $20 \%-90 \%$ of the maximum possible 


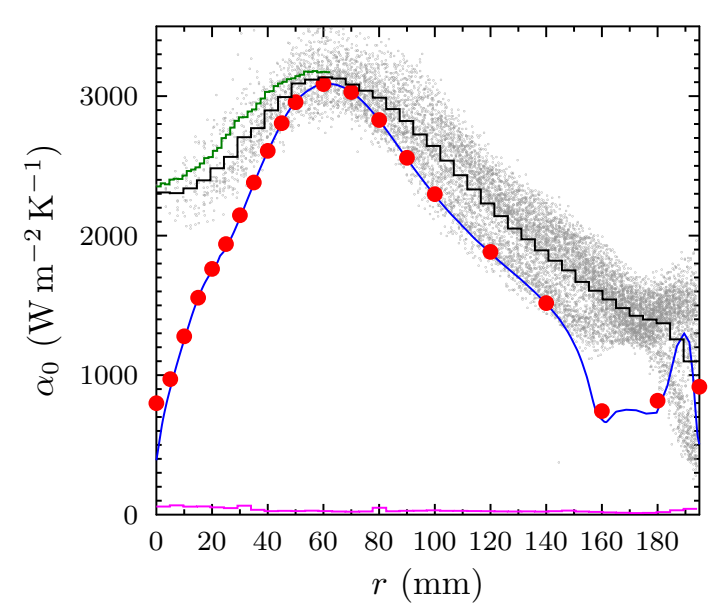

Figure 9: Experimental values of heat transfer coefficients on the surface (vessel bottom) impinged by a jet with tangential velocity component (black stepwise line) compared with the results of numerical simulations in section 2 (blue line). The shorter stepwise green line represents heat transfer coefficients measured independently with a different focus length of lens. The magenta line in the figure describes errors of the averaged experimental points (gray) in a specific location. Circles represent theoretical values which should resulted from the TOIRT measurement taking into account the lateral heat conduction.

value. The modulation proceeded with frequency $0.1 \mathrm{~Hz}$ and it was controlled by a precise sine-impulse generator. The temperature response of this plate side was measured by the infrared camera thermoIMAGER TIM 160 with sampling frequency $10 \mathrm{~Hz}$ (camera resolution $160 \mathrm{x}$ 120 points, the real distance between the measured points corresponds to approximately $3.41 \mathrm{~mm}$ and $1.04 \mathrm{~mm}$, depending on the focus length of the lens).

The measured results for two focus lengths of the lens are depicted on Figure 9. The bunch of points (10 000 approx.) represents the experimental data transformed from the Cartesian (infrared camera measurement, see Figure 8) to the cylindrical (polar) coordinate system describing the dependency of the heat transfer coefficient on the radius.

The black stepwise line in the Figure 9 represents average values in a corresponding range of the radial coordinate. In this case, the whole range of the radial coordinate has been divided into 40 equidistant sections. The blue line in the figure represents the heat transfer coefficients coming from the numerical simulation of the agitated vessel described in section 2 . The measured data show very good agreement with the numerical data as for the peak position and its magnitude. Larger discrepancies are visible on the left as well as on the right of the maximum. In both cases, the experimental values are larger than the simulated ones, especially near the stagnation point where we wanted to verify our numerical results and the literature data.

Figure 9 shows clearly that the differences between the experimental values of the heat transfer coefficients are larger in regions with smaller heat transfer intensities and in regions with larger gradients of the heat transfer coefficients which is closely related to the radial gradients of the wall temperature. In such case, the heat conduction in the heat transfer wall appears not only in the normal direction, but also in the radial direction. And the heat conduction in the radial direction (lateral conduction) is neglected in the
TOIRT method by Wandelt and Roetzel [8]. To evaluate the errors yielding from the neglect of the lateral heat conduction, we performed numerical simulations of this case in ANSYS CFD which are described in the next section.

\section{Numerical simulation of the Wandelt and Roetzel method}

We used ANSYS CFD with Fluent solver to simulate the heat conduction in the heat transfer surface represented by circular plate of diameter $392 \mathrm{~mm}$ and thickness $1 \mathrm{~mm}$ (the bottom of the agitated vessel). Figure 7 depicts the basic geometry of this task. It was modeled as an axisymmetric case. A perfect insulation, that is zero heat flux was considered as the boundary condition on the upper wall edge of the plate. The boundary condition of the third kind based on liquid temperature $300 \mathrm{~K}$ and the heat transfer coefficients gained in the numerical simulation of the agitated vessel was specified at the edge denoted as "top". A mixed boundary condition was applied to the edge "bottom". It combined the third-kind boundary condition and an oscillating heat flux. The surrounding temperature $T_{f}$ was again $300 \mathrm{~K}$ (this temperature was also used as the initial condition of the transient solution), and the heat transfer coefficient was set to $3 \mathrm{~W} \mathrm{~m}^{-2} \mathrm{~K}^{-1}$ (natural convection). The heat flux impinging the "bottom" had a sine time dependency with $10 \mathrm{~Hz}$ frequency and $10 \mathrm{~kW} \mathrm{~m}^{-2}$ amplitude. The following UDF function was used to define this boundary condition in the Fluent solver.

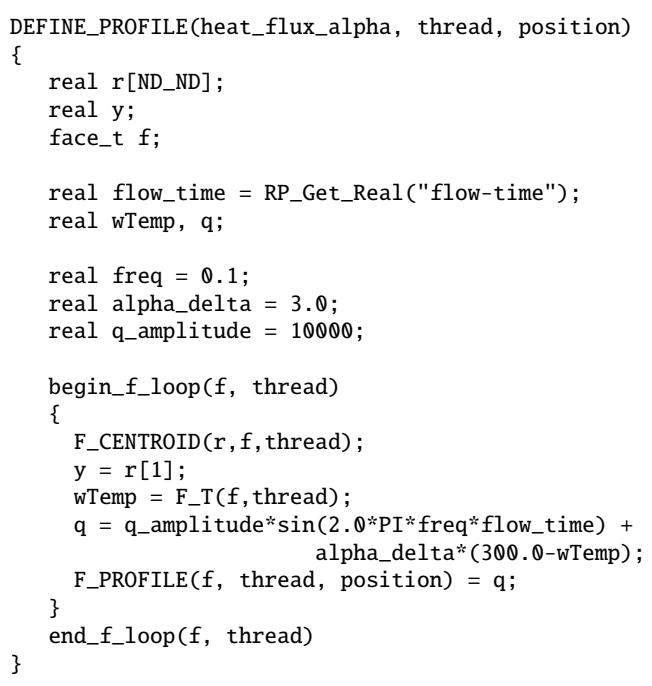

The problem was solved as a transient case with time step $0.01 \mathrm{~s}$ (first, time step $0.1 \mathrm{~s}$ was used but the resulting values of heat transfer coefficients showed $10 \%$ difference from the theoretical solution by Wandelt and Roetzel [8] even in cases when the lateral conduction can be neglected). A 2-D mesh with 40 thousand elements was created on the surface representing the axisymmetric geometry of the wall (Figure 7). During the transient solution of the temperature field in the wall, the temperature time dependency on the "bottom" edge was monitored at several discrete points just as it is monitored by the infrared camera. The black oscillating line on Figure 10 represents an example of such time dependency. The time dependency of the oscillating heat flux is represented by the blue line on the same figure (with a scaled amplitude to fit the vertical axis range which has no influence on the phase shift). 


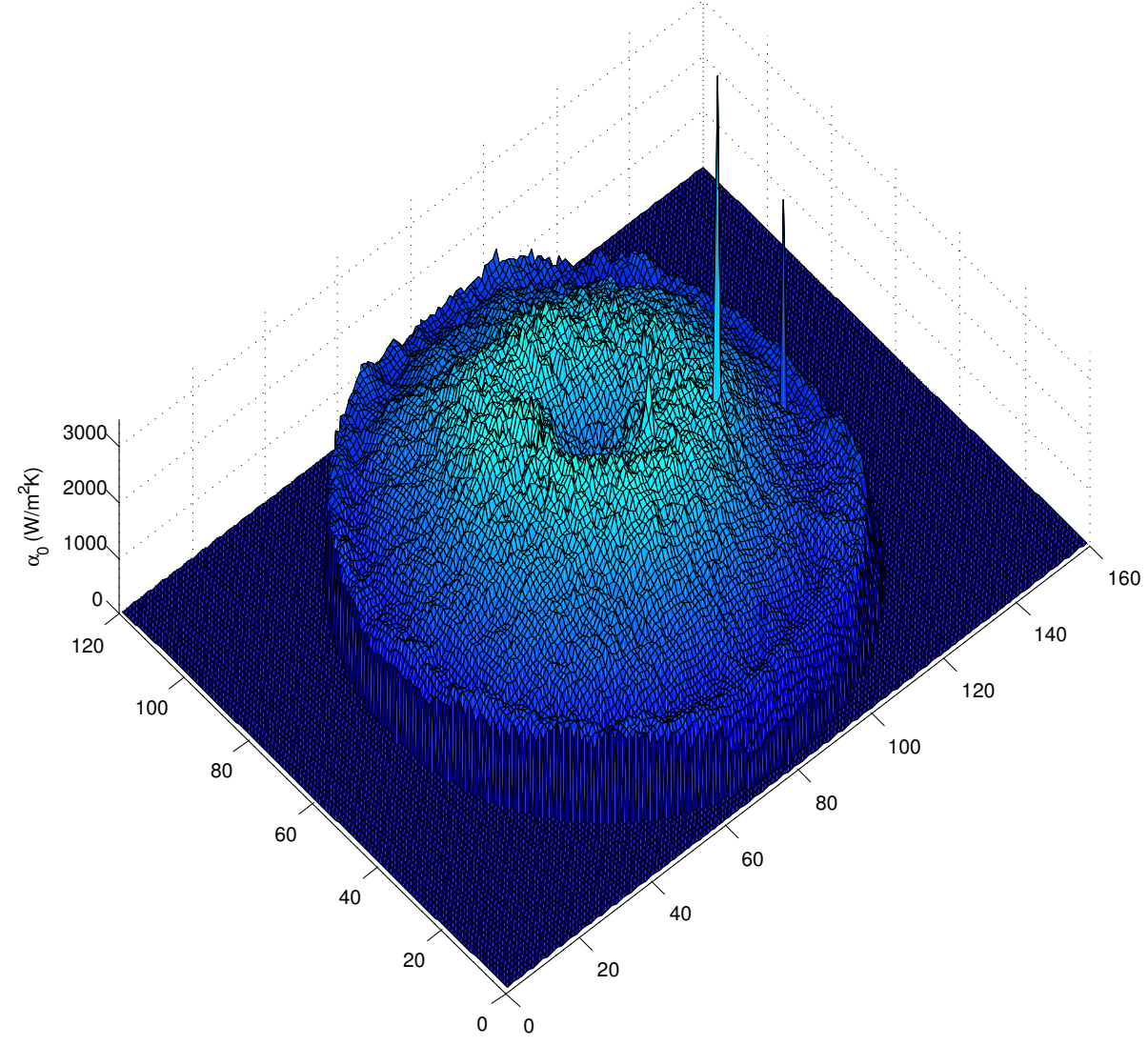

Figure 8: An illustration of the measured heat transfer coefficients at the heat transfer surface in individual points taken by the infrared camera (the size of the surface is expressed in pixels given by the camera resolution).

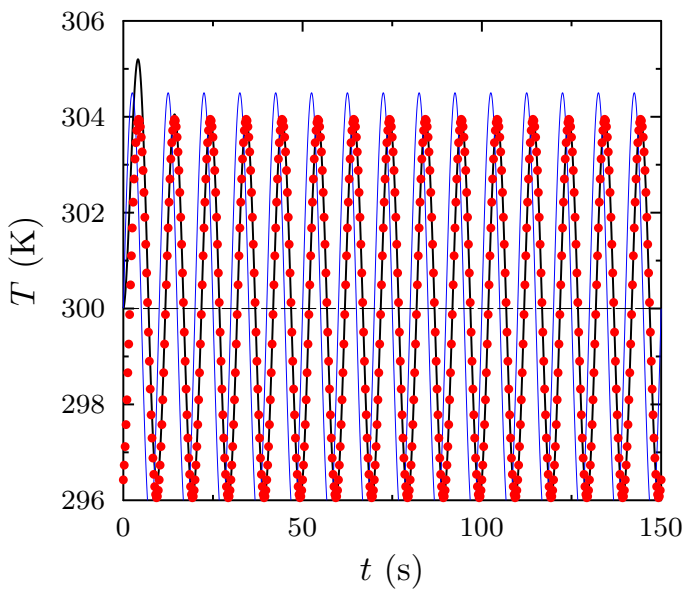

Figure 10: ANSYS CFD (Fluent) simulation results of Wandelt and Roetzel method [8] for heat transfer coefficients $1000 \mathrm{~W} \mathrm{~m}^{-2} \mathrm{~K}^{-1}$ at the impinged "top" surface and $3 \mathrm{~W} \mathrm{~m}^{-2} \mathrm{~K}^{-1}$ at the illuminated "bottom" surface. The blue line represents the oscillating heat flux from halogen lamps. The black line corresponds to the calculated temperature profile at radius $100 \mathrm{~mm}$ of this "bottom" surface. The red points represent the sine dependency of this response (for larger time values). The phase shift between the actuating (source) signal and the response is obvious here and it can be used in evaluation of the heat transfer coefficient at the impinged "top" surface.
Applying Wandelt and Roetzel method [8] on these time dependencies of the wall surface temperatures, the phase shift between the oscillating source signal and oscillating response temperature can be evaluated using Eq. (11). The red points in Figure 10 follow the measured temperature response and represent the theoretical temperature response described by Eq. (10). In this case, it can be evaluated as

$$
\begin{aligned}
T(t) & =300+3.9492 \sin [2 \pi 0.1(t-1.8007)]= \\
& =300+3.9492 \sin (2 \pi 0.1 t-1.1314) .
\end{aligned}
$$

The phase shift is 1.1314 radians in this case which corresponds to heat transfer coefficient $1000 \mathrm{~W} \mathrm{~m}^{-2} \mathrm{~K}^{-1}$ for the given geometrical and thermophysical parameters.

Processing the temperature time dependencies in all monitored points at the "bottom" edge will give us the radial profile of the heat transfer coefficients at the "top" edge, see Figure 11. The results presented here show that the values based on Wandelt and Roetzel method [8] have quite good agreement with correct heat transfer coefficients in regions with values greater than $1000 \mathrm{~W} \mathrm{~m}^{-2} \mathrm{~K}^{-1}$, that is in the prevailing part of the measured profile. Let us remind that this experimental method neglects the lateral conduction. Figure 11 demonstrates that the lateral conduction can be neglected along the whole surface except small regions near the stagnation point and the vessel wall. In these regions, the values of heat transfer coefficients fall below $1000 \mathrm{~W} \mathrm{~m}^{-2} \mathrm{~K}^{-1}$ and the lateral conduction due to the radial temperature gradients affects the measured and 


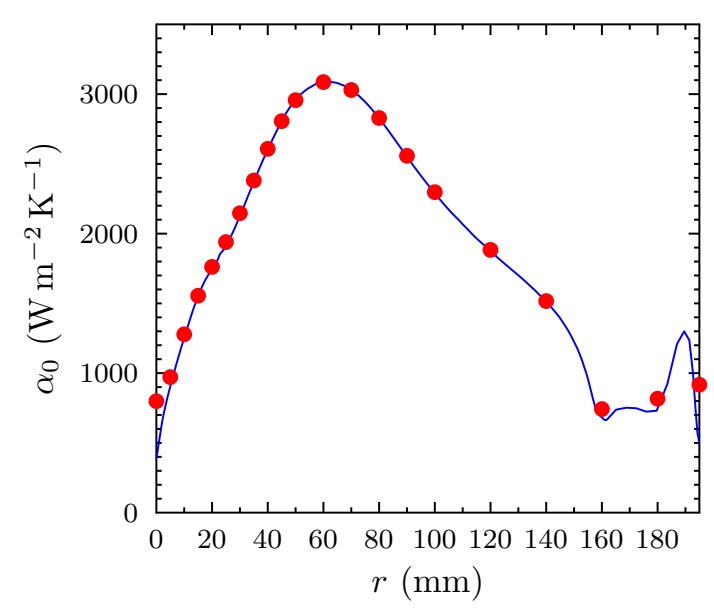

Figure 11: Numerical results including the heat conduction in the wall illuminated by an oscillating heat flux and consequent evaluation based on Wandelt and Roetzel method [8]. The continuous line represents the applied heat transfer coefficients at the "top" edge, and the discrete points were evaluated from the simulated temperature dependencies according to the Wandelt and Roetzel method [8].

evaluated values which are larger than real ones (they are almost twice larger near the stagnation point).

\section{Conclusions}

The values of heat transfer coefficients measured by the TOIRT method and evaluated according to Wandelt and Roetzel method [8] which neglects the lateral heat conduction are presented on Figure 9 (black line). The values of heat transfer coefficients including the influence of the lateral conduction (distinct points in the figure) do not improve the agreement of the simulation results with experimental data in the given system. Hence, the lateral heat conduction is probably not the reason of relatively large experimental values near the stagnation point.

A possible source of the disagreement between experimental and numerical results could lie in relatively small amplitudes of temperature oscillations, see Figure 12. This could be resolved by a more intensive heat source.

Quite good agreement was achieved in the size and position of the heat transfer maximum. The measurements have been performed several times and all experimental data were within $\pm 8 \%$ interval, indicating a relatively good repeatability of the measuring procedure.

\section{Acknowledgment}

This work has been supported by research project of the Grant Agency of Czech Republic No. 14-18955S.

\section{Nomenclature}

$a \quad$ thermal diffusivity, $a=\lambda / \varrho c_{\mathrm{P}} \quad\left(\mathrm{m}^{2} \mathrm{~s}^{-1}\right)$

$A$ surface, area of impinged plate or vessel bottom $\left(\mathrm{m}^{2}\right)$

$c_{0,1, \ldots, 4}$ constants (parameters) used in Equation (11), see Equation (13) for their definitions (-)

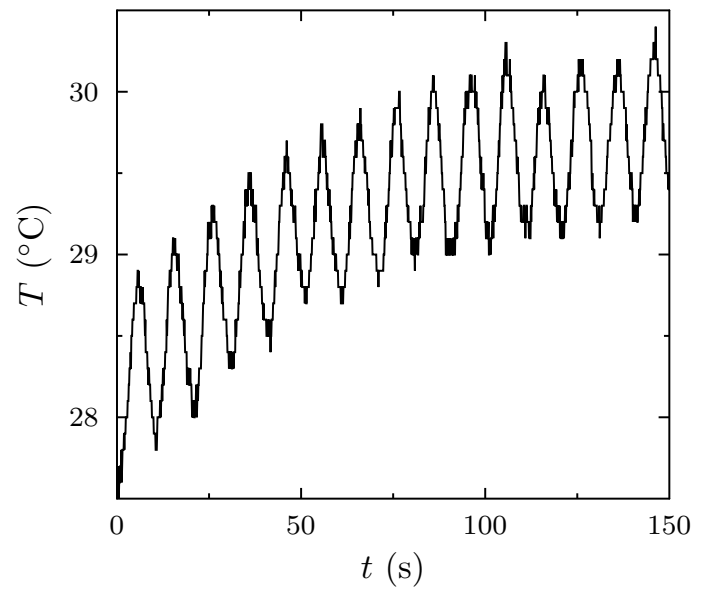

Figure 12: Time dependency of temperature taken by the infrared camera using the TOIRT method in one point on the wall. The oscillating temperature response with period 10s (frequency 0.1 $\mathrm{Hz}$ ) superposed on an "exponentially" increasing the mean temperature of the liquid due to the heat accumulation in the system. This dependency has to be transformed to a temperature response oscillating around a constant value.

$c_{\mathrm{P}} \quad$ specific heat capacity $\left(\mathrm{J} \mathrm{kg}^{-1} \mathrm{~K}^{-1}\right)$

$d$ diameter of jet nozzle or draft tube (m)

$d_{\mathrm{M}} \quad$ diameter of impeller $(\mathrm{m})$

$D \quad$ outer diameter of impinged plate or vessel bottom (m)

$f \quad$ frequency $\left(\mathrm{Hz}, \mathrm{s}^{-1}\right)$

$G_{x} \quad$ flux of axial momentum in the definition of Swirl number, see Eq. (4) $\left(\mathrm{kg} \mathrm{m} \mathrm{s}^{-2}\right)$

$G_{\varphi} \quad$ flux of angular momentum in the definition of Swirl number, see Eq. (4) $\left(\mathrm{kg} \mathrm{m}^{2} \mathrm{~s}^{-2}\right)$

$h \quad$ jet distance from the plate $(\mathrm{m})$

$h_{2} \quad$ distance of the impeller from the outlet of the draft tube $(\mathrm{m})$

$H$ height of liquid in the vessel (m)

$k \quad$ turbulent kinetic energy $\left(\mathrm{m}^{2} \mathrm{~s}^{-2}, \mathrm{~J} \mathrm{~kg}^{-1}\right)$

$N \quad$ impeller speed $\left(\mathrm{s}^{-1}, \mathrm{rpm}\right)$

$\mathrm{Nu} \quad$ Nusselt number, $\mathrm{Nu}=\alpha d / \lambda$, where heat transfer coefficient $\alpha$ is evaluated as $\alpha=q /\left(T_{\mathrm{w}}-T_{\mathrm{b}}\right) \quad(-)$

$q \quad$ heat flux $\left(\mathrm{W} \mathrm{m}^{-2}\right)$

$\hat{q} \quad$ amplitude of oscillating heat flux $\left(\mathrm{W} \mathrm{m}^{-2}\right)$

$r$ radial coordinate $(\mathrm{m})$

$r$ dimensionless parameter in Equation (11), see Equation (12) for its definition (-)

$R \quad$ outer radius of impinged plate or vessel bottom (m)

Re Reynolds number, $u_{\mathrm{b}} D / v(-)$

$S_{i j} \quad$ strain-rate tensor $\left(\mathrm{s}^{-1}\right)$

$t$ time (s)

$T$ temperature $\left({ }^{\circ} \mathrm{C}, \mathrm{K}\right)$

$T_{\mathrm{b}} \quad$ bulk temperature (average) at the jet nozzle $\left({ }^{\circ} \mathrm{C}, \mathrm{K}\right)$

$T_{\mathrm{f}} \quad$ fluid (liquid) temperature $\left({ }^{\circ} \mathrm{C}, \mathrm{K}\right)$

$T_{\mathrm{w}} \quad$ wall (boundary) temperature $\left({ }^{\circ} \mathrm{C}, \mathrm{K}\right)$

$u \quad$ velocity, axial velocity $\left(\mathrm{m} \mathrm{s}^{-1}\right)$

$u_{\mathrm{b}} \quad$ bulk (average) velocity, see Eq. (6) $\left(\mathrm{m} \mathrm{s}^{-1}\right)$

$u^{*} \quad$ dimensionless axial velocity related to the tip velocity of the impeller, $u^{*}=u /\left(\pi d_{\mathrm{M}} N\right) \quad\left(\mathrm{m} \mathrm{s}^{-1}\right)$

$w \quad$ tangential (swirl) velocity $\left(\mathrm{m} \mathrm{s}^{-1}\right)$

$w_{\mathrm{b}} \quad$ bulk tangential velocity, see Eq. (6) $\left(\mathrm{m} \mathrm{s}^{-1}\right)$

$u^{\prime} \quad$ velocity fluctuation $\left(\mathrm{m} \mathrm{s}^{-1}\right)$ 
$w^{*} \quad$ dimensionless tangential velocity related to the tip velocity of the impeller, $w^{*}=w /\left(\pi d_{\mathrm{M}} N\right) \quad\left(\mathrm{m} \mathrm{s}^{-1}\right)$

$S \quad$ Swirl number, see Eqs. (3), (5) (-)

$x, y, z$ spatial coordinates of the Cartesian coordinate system $(\mathrm{m})$

$\alpha \quad$ heat transfer coefficient $\left(\mathrm{W} \mathrm{m}^{-2} \mathrm{~K}^{-1}\right)$

$\gamma \quad$ intermittency $(-)$

$\Gamma \quad$ diffusivity in the user-defined scalar equation $\left(\mathrm{kg} \mathrm{m}^{-1} \mathrm{~s}^{-1}\right)$

$\delta \quad$ width of impinged plate $(\mathrm{m})$

$\delta_{i j} \quad$ Kronecker unity tensor $(-)$

$\varepsilon \quad$ dissipation rate of turbulent kinetic energy $\left(\mathrm{m}^{2} \mathrm{~s}^{-3}\right)$

$\lambda$ thermal conductivity $\left(\mathrm{W} \mathrm{m}^{-1} \mathrm{~K}^{-1}\right)$

$\mu \quad$ dynamic viscosity (Pa s, $\mathrm{kg} \mathrm{m}^{-1} \mathrm{~s}^{-1}$ )

$\mu_{\mathrm{t}}$ turbulent (eddy) dynamic viscosity

(Pa s, $\mathrm{kg} \mathrm{m}^{-1} \mathrm{~s}^{-1}$ )

$v \quad$ kinematic viscosity, $v=\mu / \varrho\left(\mathrm{m}^{2} \mathrm{~s}^{-1}\right)$

$\xi \quad$ dimensionless width, $\xi=\delta \sqrt{\omega / 2 a}$ (-)

$\varrho \quad$ density $\left(\mathrm{kg} \mathrm{m}^{-3}\right)$

$\phi \quad$ general scalar variable in the user-defined scalar equation $(-)$

$\varphi \quad$ phase shift $(-)$

$\psi_{0} \quad$ dimensionless parameter used in Equation (11), see Equation (12) for its definition (-)

$\omega \quad$ specific dissipation rate of turbulent kinetic energy, $\omega=\varepsilon / k \quad\left(\mathrm{~s}^{-1}\right)$

$\omega \quad$ angular frequency of oscillating heat flux, $\omega=2 \pi f$ $\left(\mathrm{s}^{-1}\right)$

\section{References}

1. V. Katti, S. Prabhu, Int. J. Heat Mass Transfer 51, 4480 (2008)

2. M. Behnia, S. Parneix, Y. Shabany, P.A. Durbin, Int. J. Heat Fluid Flow 20, 1 (1999)

3. D. Lytle, B. Webb, Int. J. Heat Mass Transfer 37, 1687 (1994)

4. J. Baughn, S. Shimizu, ASME Journal of Heat Transfer 111, 1096 (1989)

5. P. Vlček, T. Jirout, CFD simulation of flow in mixing equipment with draft tube, in CHISA conference (Seč, Czech Republic, 2015)

6. V.I. Terekhov, Y.M. Mshvidobadze, Thermal Science 20, suppl. 1, 35 (2016)

7. Z.U. Ahmed, Y.M. Al-Abdeli, M.T. Matthews, Computers \& Fluids 118, 255 (2015)

8. M. Wandelt, W. Roetzel, Lockin thermography as a measurement technique in heat transfer, in QIRT 96 Eurotherm Series 50 (1997), pp. 189-194

9. D. Wilcox, Turbulence Modeling for CFD (DCW Industries, Inc., 2006)

10. J.O. Hinze, Turbulence (McGraw-Hill Publishing Co., New York, 1975)

11. Petera, K., EPJ Web of Conferences 114, 02091 (2016)

12. M. Kato, B. Launder, The modelling of turbulent flow around stationary and vibrating square cylinders, in Ninth Symposium on "Turbulent Shear Flows" (1993)

13. ANSYS Fluent, ANSYS Fluent Theory Guide, ANSYS, Inc., Release 16.0 (2015)
14. M. Mahmood, Heat transfer from swirling impinging jets, Ph.D. thesis, Cranfield Institute of Technology (1980)

15. S. Freund, Local Heat Transfer Coefficients Measured with Temperature Oscillation IR Thermography, Ph.D. thesis, Hamburg (2007)

16. S. Freund, S. Kabelac, Measurement of local convective heat transfer coefficients with temperature oscilation IR thermography and radiant heating, in Proceedings of HT2005 (2005), pp. 1-7

17. S. Freund, A.G. Pautsch, T.A. Shedd, S. Kabelac, Int. J. Heat Mass Transfer 50, 1953 (2007)

18. S. Freund, S. Kabelac, Int. J. Heat Mass Transfer 53, 3764 (2010) 